\title{
OPEN Cell-penetrating peptide-mediated cell entry of H5N1 highly pathogenic avian influenza virus
}

\author{
Naoki Kajiwara ${ }^{1,4}$, Namiko Nomura ${ }^{1,4}$, Masako Ukaji ${ }^{1,4}$, Naoki Yamamoto ${ }^{2}$, \\ Michinori Kohara ${ }^{2}$, Fumihiko Yasui ${ }^{2}$, Yoshihiro Sakoda ${ }^{3}$, Hiroshi Kida ${ }^{3}$ \& Futoshi Shibasaki ${ }^{1,5} \bowtie$
}

H5N1 highly pathogenic avian influenza virus (HPAIV) poses a huge threat to public health and the global economy. These viruses cause systemic infection in poultry and accidental human infection leads to severe pneumonia, associated with high mortality rates. The hemagglutinin (HA) of H5N1 HPAIV possesses multiple basic amino acids, as in the sequence RERRRKKR at the cleavage site; however, the role of this motif is not fully understood. Here, we showed that a 33-amino acid long peptide derived from HA of H5N1 HPAIV (HA314-46) has the potential to penetrate various cells and lung tissue through a sialic acid-independent endocytotic pathway. Mutant peptide analyses revealed that the cysteine residue at position 318 and multiple basic amino acids were essential for the cell-penetrating activity. Moreover, reassortant viruses possessing H5 HA could enter sialic aciddeficient cells, and virus internalisation was facilitated by cleavage with recombinant furin. Thus, our findings demonstrate that the HA314-46 motif exhibits cell-penetrating activity through a sialic acidindependent cell entry mechanism.

Influenza A viruses are responsible for the seasonal epidemics and occasional pandemics in humans and animals ${ }^{1}$. These viruses have a segmented, single-stranded, negative-sense RNA genome within the envelope ${ }^{1}$. Among many subtypes, H5N1 highly pathogenic avian influenza viruses (HPAIVs) are a serious threat to public health and the global economy ${ }^{2}$. Since the first human infection in Hong Kong ${ }^{3,4}$, H5N1 HPAIVs have caused hundreds of hospitalisations and deaths with a high fatality rate ${ }^{5,6}$. Furthermore, the emergence of other neuraminidase subtypes such as $\mathrm{H} 5 \mathrm{~N} 6$ and $\mathrm{H} 5 \mathrm{~N} 8$, arising from the same ancestral H5N1 virus, has threatened human and animal health ${ }^{7,8}$. Hence, a better understanding of the interspecies transmission mechanism is crucial to prevent and control the spread of HPAIVs with H5 subtypes.

Influenza A virus infection is initiated by the binding of hemagglutinin (HA) to cell surface receptors, sialylated glycoconjugates ${ }^{9}$. There are two main forms that determine the host tropism: sialic acid- $\alpha(2,3)$-galactose for avian cells and sialic acid- $\alpha(2,6)$-galactose for mammalian cells ${ }^{10}$. Following cell entry through endocytosis, the HA proteins change conformation under low $\mathrm{pH}$ conditions in the endosome, which causes fusion of viralendosomal membranes ${ }^{9}$. For membrane fusion to occur, the precursor protein $\mathrm{HA} 0$ must become proteolytically cleaved into HA1 and HA2 subunits in the trans-Golgi network or on the plasma membrane ${ }^{11}$. In contrast with the HA proteins of low pathogenic viruses, the HA proteins of H5N1 HPAIV s contain multiple basic amino acids at the cleavage site ${ }^{12}$. This characteristic sequence is cleaved by ubiquitous cellular proteases, such as furin and proprotein convertase $6^{13,14}$, suggesting systemic infection in poultry ${ }^{15}$. Thus, the amino acid sequence of HA cleavage site is a key determinant for organ tropism and pathogenicity of influenza A viruses.

The HA cleavage site motif of H5N1 HPAIV resembles cationic cell-penetrating peptides (CPPs) such as trans-activator of transcription (TAT) from human immunodeficiency virus type 1 (HIV-1) ${ }^{16}$. The representative amino acid sequence of HA cleavage site motif from H5N1 HPAIV is RERRRKKR and that of TAT peptide is YGRKKRRQRRR. CPPs can efficiently transport a wide variety of biologically active conjugates including proteins, peptides, nucleic acids, small chemical compounds, and nanoparticles into cells via energy-dependent endocytosis and/or energy-independent direct penetration ${ }^{17,18}$. In addition to TAT peptide ${ }^{19,20}$, peptides with

\footnotetext{
${ }^{1}$ Molecular Medical Research Project, Department of Genome Medicine, Tokyo Metropolitan Institute of Medical Science, 2-1-6, Kamikitazawa, Setagaya-ku, Tokyo 156-8506, Japan. ${ }^{2}$ Department of Microbiology and Cell Biology, Tokyo Metropolitan Institute of Medical Science, Tokyo, Japan. ${ }^{3}$ Laboratory of Microbiology, Department of Disease Control, Graduate School of Veterinary Medicine, Hokkaido University, Sapporo 060-0818, Japan. ${ }^{4}$ Present address: Neurovirology Project, Department of Diseases and Infection, Tokyo Metropolitan Institute of Medical Science, Tokyo, Japan. ${ }^{5}$ Present address: Center for Medical Research Cooperation, Tokyo Metropolitan Institute of Medical Science, Tokyo, Japan. ${ }^{\circledR}$ email: shibasaki-ft@igakuken.or.jp
} 
cell-penetrating activity have been found in other viruses, such as herpes simplex virus type $1^{21}$, dengue virus ${ }^{22}$, hepatitis B virus ${ }^{23,24}$, and human papillomavirus ${ }^{25,26}$. However, little is known about the functional roles of these peptides during virus infection. For example, TAT is secreted by HIV-infected cells, but the role of the secreted TAT in virus replication or pathogenesis remains elusive ${ }^{27}$.

In the present study, we tested the hypothesis that the cell-penetrating activity of HA cleavage site motif stimulates a sialic acid-independent cellular entry of H5N1 HPAIV.

\section{Results}

The C-terminal domain of HA1 protein from H5N1 HPAIV has an ability to internalise into cells. In general, the activities of CPPs are not selective ${ }^{17}$. We first investigated whether the C-terminal domain of H5N1 HPAIV HA1 protein has cell-penetrating activity. For these experiments, HA314-46 peptide comprising the wild-type C-terminus of HA1 protein from H5N1 HPAIV and the HA314-38 peptide lacking the multiple basic amino acids were used (Fig. 1a). TAT peptide was used as a positive control for CPP assay. These peptides were labelled with fluorescein isothiocyanate (FITC). Confocal microscopic examination of COS-7 cells incubated with HA314-46 or TAT peptide showed that the spotted fluorescence signal was localised in both the cytoplasm and nucleus (Fig. $1 \mathrm{~b}$ and Supplementary Fig. S1). In contrast, there was no internalisation of HA314-38 peptide. To confirm the CPP activity of HA314-46 peptide, KU812 cells were also treated with these peptides. Similar to TAT, the HA314-46 peptide could also penetrate into the cells. However, HA314-38 peptide was not cell-permeable. To quantify the intensity of cell penetration, geometric mean fluorescence intensity (MFI) in viable cells was measured by flow cytometry. Cells incubated with HA314-46 or TAT peptide displayed a significant increase of MFI, while HA314-38 mutant peptide lost the ability to penetrate cells (Fig. 1c). We further evaluated the duration of peptide uptake. The HA314-46 peptide uptake was maximised at 120 min and remained until 240 min (Supplementary Fig. S2). Conversely, the cell-penetrating activity of TAT peptide peaked at $30 \mathrm{~min}$. HA314-38 mutant peptide was not internalised following incubation for $240 \mathrm{~min}$. Cationic CPPs are known to non-specifically bind to the outside of the cell membrane, leading to false-positive results ${ }^{28}$. To remove the peptides absorbed to cell surface, KU812 cells were treated with $0.1 \%$ trypsin after peptide uptake. The increase of MFI in the case of HA314-46 or TAT peptide persisted even after trypsin treatment (Supplementary Fig. S3), indicating the intracellular localisation of the peptide.

H5N1 HPAIV-derived HA314-46 peptide exhibits a broad cell tropism. Next, we examined the cell specificity of H5N1 HPAIV-derived HA314-46 peptide using a wide variety of cell lines of different origins. Cells were incubated with HA314-38, HA314-46, or TAT peptides and then geometric MFI in viable cells was determined by flow cytometry. The results showed that HA314-46 peptide was non-selectively internalised into adherent (A549, HeLa, NIH/3T3, J774A.1, COS-7, and MDCK), and non-adherent (KU812, Jurkat, Raji, U937, THP-1, and HL-60) cell lines, as is the case with TAT peptide (Supplementary Table S1). In non-adherent cell lines, HA314-46 peptide was observed to be highly permeable in KU812 cells, whereas it showed low incorporation into HL-60 cells at the same dose. To investigate the incorporation of HA314-46 peptide into primary cells, mouse splenocytes were prepared and subjected to cell penetration assay. Cell surface markers were utilised for the separation of cell populations: macrophages, $\mathrm{CD} 11 \mathrm{~b}^{+} \mathrm{F} 4 / 80^{+} \mathrm{MHC}$ class $\mathrm{II}^{+}$; $\mathrm{CD}^{+} \mathrm{T}$ cells, $\mathrm{CD}^{+} \mathrm{CD}^{+}$; $\mathrm{CD}^{+}$ $\mathrm{T}$ cells, $\mathrm{CD}^{+} \mathrm{CD}^{+}$; and $\mathrm{B}$ cells, $\mathrm{CD} 19^{+} \mathrm{B} 220^{+}$(Supplementary Fig. S4). These cell surface markers could be stained with antibodies even following a $0.1 \%$ trypsin treatment. Flow cytometric analysis revealed that HA31446 peptide was able to penetrate immune cells including macrophages, $\mathrm{CD}^{+}$and $\mathrm{CD}^{+} \mathrm{T}$ cells, as well as $\mathrm{B}$ cells (Fig. 2a). We further tested the cell-penetrating activity of HA314-46 peptide in vivo. For this purpose, anaesthetised mice were intranasally administered with peptides to monitor the distribution in lung tissues. Tissue sections showed the wide distribution of HA314-46 and TAT peptides in lungs (Fig. 2b). In the same model, non-permeable HA314-38 peptide was not detected in the lungs as the peptide was washed out during the preparations of tissue sections.

Cysteine residue and multiple basic amino acids are necessary for HA314-46 peptide internalisation. Using several peptides, we attempted to determine the essential motif of the HA314-46 peptide. The amino acid sequence of each peptide is summarised in Table 1. In this screening, KU812 cells were exposed to HA peptides of various lengths. After washing and trypsinisation, geometric MFI was measured using flow cytometry. Two HA peptides (HA318-46 and HA314-46) permeated through the plasma membrane and resulted in an increase of MFI in viable cells (Fig. 3a). These peptides included a 29-amino acid residue region, spanning from 318 to 346 of HA protein from H5N1 HPAIV. Meanwhile, the shorter HA peptides, such as HA339-46, did not exhibit cell-penetrating activity. To identify amino acid residues essential for the activity of HA314-46 peptide, we replaced the cysteine residue at position 318 with serine (C318S) or alanine (C318A). Strikingly, C318S or C318A mutations abolished the cell-penetrating activity of HA314-46 peptide (Fig. 3b). In UniProt protein knowledgebase (Q5EP31), cysteine residues are known to form disulphide bonds at position 294 and 318 . To determine whether disulphide bond formation affects the cell-penetrating activity, HA peptides were incubated in the presence or absence of dimethyl sulfoxide (DMSO) ${ }^{29}$. In contrast to the C318S- and C318A-mutant peptides, HA314-38 and HA314-46 peptides produced homodimers by DMSO oxidation (Supplementary Fig. S5a and S5b). Mass spectrometry analyses showed that the peak area ratio of homodimer/monomer in HA314-46 peptide was increased by DMSO oxidation (DMSO (-) 0.11 vs DMSO (+) 0.91). In HA314-46 (C318S) mutant peptide, no difference was observed in peak area ratio of homodimer/monomer between DMSO (-) and DMSO (+). DMSO-treated HA314-46 peptide exhibited a twofold increase in MFI compared to the non-treated peptide (Supplementary Fig. S5c), indicating the uptake of homodimers containing two FITC molecules. 
a

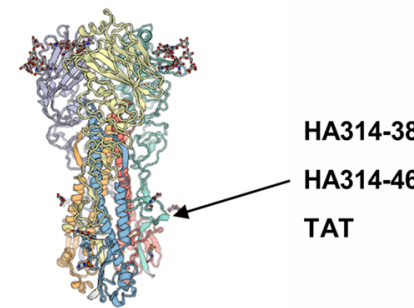

TIGECPKYVKSNRLVLATGLRNSPQ

TIGECPKYVKSNRLVLATGLRNSPQRERRRKKR

YGRKKRRQRRR

b

(-)

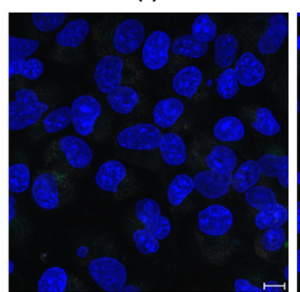

HA314-38

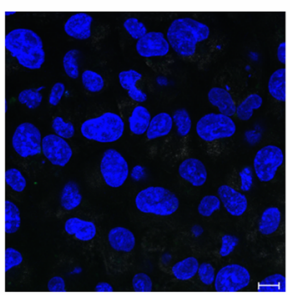

HA314-46
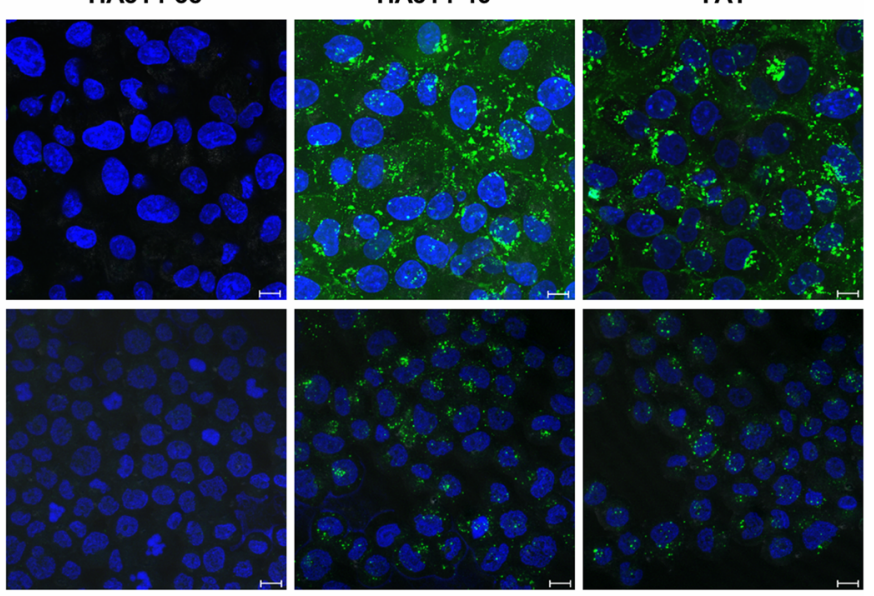

C

cos-7
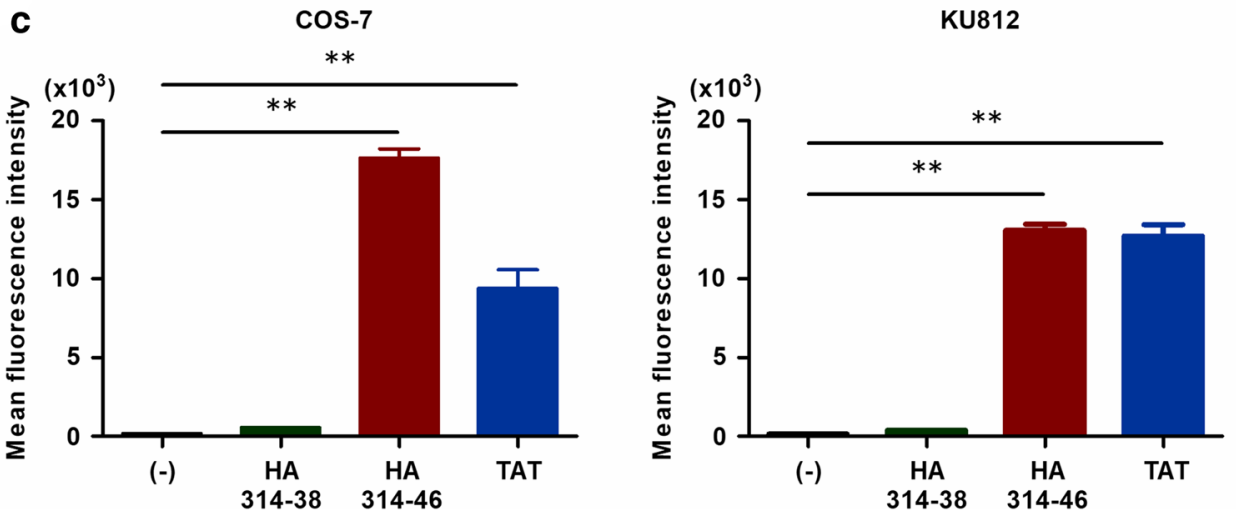

Figure 1. H5N1 HPAIV-derived HA314-46 peptide exhibits cell-penetrating activity. (a) Three-dimensional structure of HA protein and amino acid sequences of H5N1 HPAIV-derived HA314-38, HA314-46, and HIV1-derived TAT peptides. The structure and sequence were obtained from the SWISS-MODEL Repository ${ }^{50}$ (https://swissmodel.expasy.org/repository/uniprot/D9I6N5) and the UniProt database (Protein ID; D9I6N5), respectively. Red-coloured residues represent multiple basic amino acids in HA314-46 and TAT peptides. (b,c) Cell-penetrating activity of HA314-46 peptide in COS-7 and KU812 cells. COS-7 and KU812 cells were incubated with $10 \mu \mathrm{g} / \mathrm{mL}$ of FITC-conjugated peptides at $37^{\circ} \mathrm{C}$ for $60 \mathrm{~min}$. Internalisation of the peptides was examined using confocal microscopy (b). Representative images from three experiments are shown. Green, peptide; Blue, nucleus. Scale bar, $10 \mu \mathrm{m}$. Mean fluorescence intensity (MFI) of FITC in viable cells was measured by flow cytometry $(\mathbf{c})$. Data are presented as mean $+\operatorname{SEM}(n=3)$. Asterisks indicate significant increase by oneway ANOVA with Bonferroni's multiple comparison test. ${ }^{* *} p<0.01$.

Next, we examined the functional importance of multiple basic amino acids in greater detail. For this experiment, we deleted one or two basic amino acids from the C-terminus of HA314-46 peptide and found that the cell-penetrating activity of HA314-46 was markedly decreased (Fig. 3c). Specifically, it was reduced to one-third in HA314-45 peptide, while HA314-44 peptide was unable to permeate cells. In addition, we investigated whether HA314-46 activity was affected by the mutations of multiple basic amino acids found in naturally occurring isolates of H5 subtype. All HA314-46 mutant peptides retained the ability to enter cells, yet the cell-penetrating activities were attenuated by the diverse mutations (Fig. 3d). 

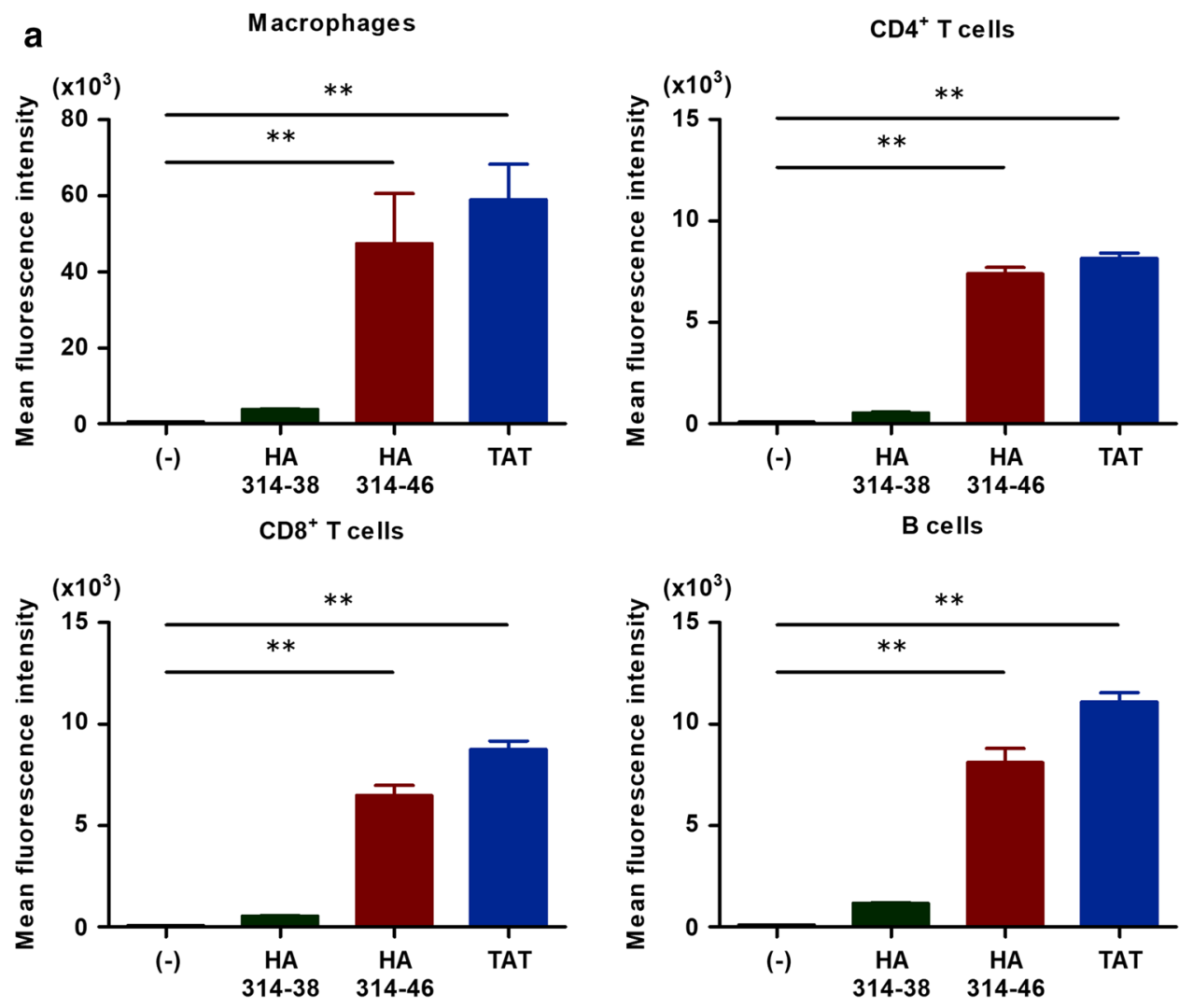

b

$(-)$

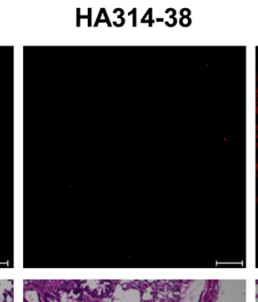

HA314-46

TAT

IHC
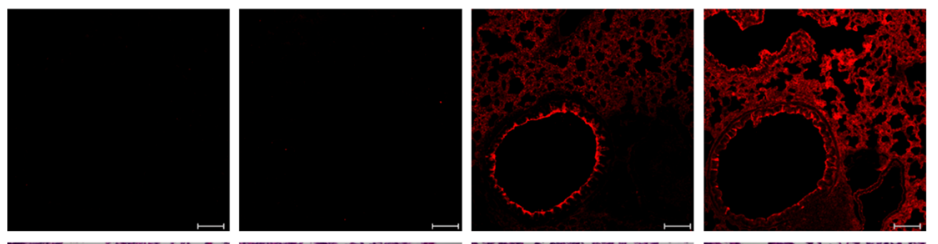

H\&E
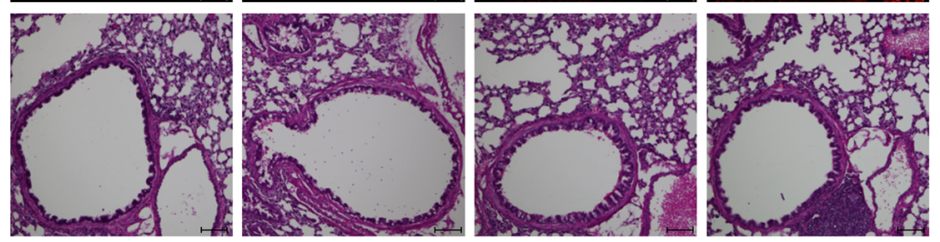

Figure 2. HA314-46 peptide penetrates several different types of cells and mouse lung tissue. (a) Cellpenetrating activity of HA314-46 peptide in mouse primary cells. Splenocytes were freshly isolated from $\mathrm{C} 57 \mathrm{BL} / 6 \mathrm{~N}$ mice and were incubated with or without $10 \mu \mathrm{g} / \mathrm{mL}$ of FITC-conjugated peptides for $60 \mathrm{~min}$ at 37 ${ }^{\circ} \mathrm{C}$. MFI of FITC in each cell population was analysed by flow cytometry. Data are presented as mean + SEM $(\mathrm{n}=4)$. Asterisks show significant increase by one-way ANOVA with Bonferroni's multiple comparison test. ${ }^{* *} p<0.01$. (b) Peptide distribution in the lung tissue of mouse intranasal inhalation model. C57BL/6 N mice were intranasally exposed with $25 \mu \mathrm{g}$ of FITC-conjugated peptides or saline (-). Lung frozen sections were stained with anti-fluorescein/Oregon Green polyclonal antibody and Alexa Fluor 555-conjugated secondary antibody for eliminating autofluorescence in the sections. The distribution of peptides was examined by confocal microscopy. Representative images from five experiments are shown. Red, peptide. Scale bar, $100 \mu \mathrm{m}$. Counterstaining of the serial section was done with H\&E dyes.

HA314-46 peptide utilises endocytosis to penetrate cells. Next, we examined the cellular uptake mechanism of HA314-46 peptide. To determine whether this peptide is internalised by endocytosis or direct penetration, KU812 cells were incubated with peptides at 37 and $16^{\circ} \mathrm{C}$. The internalisation of HA314-46 peptide was markedly reduced at $16^{\circ} \mathrm{C}$, which was consistent with the case of nona-L-arginine (R9), the prototype of cationic CPP (Fig. 4a). To reveal the major endocytic pathway of HA314-46 uptake, we tested the effect of 5-(N-Ethyl- $N$-isopropyl) amiloride (EIPA), a macropinocytosis inhibitor. When the cells were treated with EIPA, the cell-penetrating activity of HA314-46 was inhibited in a dose-dependent manner (Fig. 4b). Similarly, 


\begin{tabular}{|l|l|}
\hline Peptides & Amino acid sequences \\
\hline HA314-46 & TIGECPKYVKSNRLVLATGLRNSPQRERRRKKR \\
\hline HA339-46 & RERRRKKR \\
\hline HA333-46 & LRNSPQRERRRKKR \\
\hline HA329-46 & LATGLRNSPQRERRRKKR \\
\hline HA325-46 & NRLVLATGLRNSPQRERRRKKR \\
\hline HA321-46 & YVKSNRLVLATGLRNSPQRERRRKKR \\
\hline HA318-46 & CPKYVKSNRLVLATGLRNSPQRERRRKKR \\
\hline HA314-46 (C318S) & TIGESPKYVKSNRLVLATGLRNSPQRERRRKR \\
\hline HA314-46 (C318A) & TIGEAPKYVKSNRLVLATGLRNSPQRERRRKKR \\
\hline HA314-38 & TIGECPKYVKSNRLVLATGLRNSPQ \\
\hline HA314-44 & TIGECPKYVKSNRLVLATGLRNSPQRERRRK \\
\hline HA314-45 & TIGECPKYVKSNRLVLATGLRNSPQRERRRKK \\
\hline HA314-46 (R341G) & TIGECPKYVKSNRLVLATGLRNSPQREGRRKKR \\
\hline HA314-46 (R341S) & TIGECPKYVKSNRLVLATGLRNSPQRESRRKKR \\
\hline HA314-46 (R339G+K344R) & TIGECPKYVKSNRLVLATGLRNSPQGERRRRKR \\
\hline HA314-46 (K345del) & TIGECPKYVKSNRLVLATGLRNSPQRERRRKR \\
\hline TAT & YGRKKRRQRRR \\
\hline R9 & RRRRRRRRR \\
\hline
\end{tabular}

Table 1. List of peptides for CPP assay. Cysteine residue and multiple basic amino acids are shown in bold font. The underlined text indicates the mutation sites observed in naturally occurring isolates of H5 subtype.

the cell-penetrating activity of R9, which is partially mediated by macropinocytotic pathway ${ }^{30}$, was also inhibited by EIPA.

Sialic acids are not necessary for HA314-46 peptide internalisation. We further investigated the uptake mechanism of HA314-46 peptide using sialidase and sialic acid-deficient cells. To determine the levels of cell surface sialic acids, which bind to influenza HA proteins, KU812 cells were stained by Maackia amurensis (MAA) lectin for sialic acid- $\alpha(2,3)$-galactose or Sambucus nigra (SNA) lectin for sialic acid- $\alpha(2,6)$-galactose. MFI was significantly increased in the cells stained with MAA lectin, but not SNA lectin (Supplementary Fig. S6a). Consequently, KU812 cells predominantly express sialic acid- $\alpha(2,3)$-galactose on the cell surface. Next, KU812 cells were pre-treated with bacterial sialidase to test whether sialic acid residues are associated with HA314-46 incorporation. As expected, sialidase treatment led to a marked reduction in MAA-binding (Supplementary Fig. S6b), showing that $\alpha 2,3$-linked sialic acids were removed from the cell surface. However, the cell-penetrating activity of HA314-46 was not blocked by desialylation with sialidase (Supplementary Fig. S6c). To confirm these findings, CHO-K1 and Lec 8 mutant cell lines were used. We also utilised A549 cells as a positive control for lectin staining ${ }^{31}$. In CHO-K1 cells, high level of sialic acid- $\alpha(2,3)$-galactose was expressed, while sialic acid$a(2,6)$-galactose was not detected on the cell surface (Fig. 5a). The expressions of these sialic acid residues were absent in Lec8 cells, which is defective in the transport of UDP-galactose ${ }^{32}$. When these cells were incubated with HA314-46 or R9 peptides, peptide uptake was not decreased in Lec 8 cells (Fig. 5b). Following these experiments, we assessed the effect of trypsin pre-treatment on HA314-46 incorporation. Pre-treatment with TPCK-trypsin inhibited the uptake of HA314-46 peptide in a dose-dependent manner (Supplementary Fig. S7). Proteoglycans play a critical role in the cellular uptake of oligo-arginine peptide ${ }^{33}$; and to evaluate that role, we used pgsA-745 cell line which is deficient in xylosyltransferase ${ }^{34}$ and does not produce proteoglycans. In comparison to CHOK1 cells, HA314-46 and R9 uptakes were greatly reduced in pgsA-745 cells (Fig. 5b).

HA314-46 activity promotes entry of H5-subtype reassortant virus into cells. Next, we examined the role of HA314-46 activity in H5-subtype influenza virus infection. Several reassortant viruses were generated by reverse genetics (Table 2). PR8, comprising all A/Puerto Rico/8/1934 (H1N1) genes, served as a parental control virus. UT3040HA (R339G)/PR8 carried an R339G-mutated HA gene of the A/Vietnam/ UT3040/2004 (H5N1) virus and the remaining genes of A/Puerto Rico/8/1934 (H1N1). These viruses were expanded in MDCK cells in the presence of exogenous trypsin or furin. Furin cleaves many protein precursors at the C-terminus of a consensus sequence (R-X-R/K-R $)^{11}$. Hence, the arginine residue at position 339 of UT3040HA was replaced with glycine to avoid being cleaved at the centre of multiple basic amino acids by furin. In UT3040HA (R339G)/PR8 viruses, trypsin would cut multiple basic amino acids at random, whereas furin was predicted to cleave precisely at position 346. Using CHO-K1 and Lec8 cells, we investigated the ability of reassortant virus to invade these cells. As expected, fluorescent microscopic and flow cytometric analyses showed that $\mathrm{CHO}-\mathrm{K} 1$ cells were susceptible to all reassortant viruses (Fig. 6a). In comparison with trypsin-treated UT3040HA (R339G)/PR8 virus, viral nucleoprotein-positive cells were elevated in furin-treated one. A similar result was obtained when Lec8 cells were incubated with the H5-subtype reassortant viruses (Fig. 6b). Furin processing significantly enhanced the internalisation of UT3040HA (R339G)/PR8 virus compared to those with 

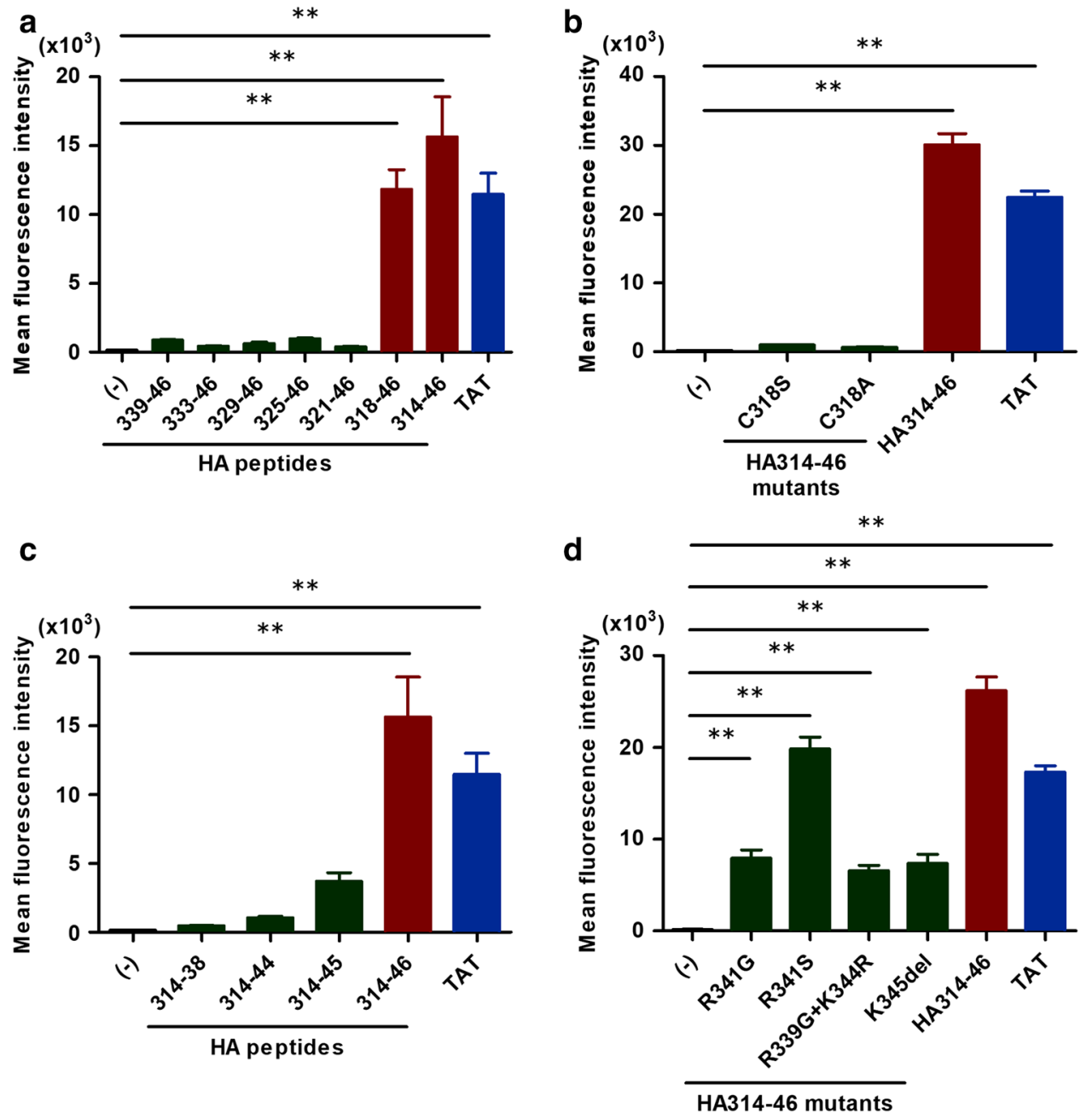

Figure 3. Cysteine residue and/or multiple basic amino acid mutations impair the cell-penetrating activity of HA314-46 peptide. (a) Screening of membrane-permeable HA peptide sequences. KU812 cells were incubated with different lengths of HA peptides or a TAT peptide. (b) Cell-penetrating activities of cysteine-substitution mutants of HA314-46 peptide. KU812 cells were incubated with cysteine-substitution mutants of HA314-46 (C318S or C318A), HA314-46, or TAT peptide. (c) Cell-penetrating activities of C-terminal basic amino acid deletion mutants of HA314-46 peptide. KU812 cells were incubated with HA314-38, HA314-44, HA314-45, HA314-46, or TAT peptides. (d) Cell-penetrating activities of C-terminal amino acid mutants observed in naturally occurring isolates of H5 subtype. KU812 cells were incubated with intact or mutant HA314-46 or TAT peptide. After incubation with $10 \mu \mathrm{g} / \mathrm{mL}$ of FITC-conjugated peptides at $37^{\circ} \mathrm{C}$ for $60 \mathrm{~min}$, the cells were subjected to flow cytometric analysis to measure MFI of FITC. Data are presented as mean + SEM ( $n=3$ or 4). Asterisks indicate significant increase by one-way ANOVA with Bonferroni's multiple comparison test. ${ }^{* *} p<0.01$.

trypsin digestion. Although sialic acid-deficient Lec8 cells were highly resistant to invasion of PR8, UT3040HA (R339G)/PR8 viruses were able to enter these cells.

We further investigated the role of proteoglycans in the UT3040HA (R339G)/PR8 virus entry using the pgsA-745 mutant cell line. The percentage of nucleoprotein-positive cells was not impaired in pgsA-745 cells (Supplementary Fig. S8). Next, we examined the effect of EIPA on the entry of furin-treated UT3040HA (R339G)/ PR8 virus into Lec8 cells. The analyses using fluorescent microscopy and flow cytometry indicated that the nucleoprotein-positive cells were significantly reduced in the presence of more than $20 \mu \mathrm{M} \mathrm{EIPA} \mathrm{(Fig.} 6 \mathrm{c}$ ). Total cell number and cell viability were not affected by EIPA treatment (Supplementary Fig. S9a).

To determine if reassortant viruses can replicate in Lec8 cells, the virus-inoculated cells were cultured in serum-containing medium for 24 and $48 \mathrm{~h}$. In this experiment, Lec8 cells became confluent at $24 \mathrm{~h}$ and total cell number was comparable between 24 and $48 \mathrm{~h}$ cultures (Supplementary Fig. S9b). PR8 could not proliferate in this condition as HA protein was not cleaved. In contrast, exposure of UT3040HA (R339G)/PR8 to Lec8 cells considerably expanded the proportion of nucleoprotein-positive cells at $48 \mathrm{~h}$ post-infection (Fig. $6 \mathrm{~d}$ ), indicating that UT3040HA (R339G)/PR8 viruses are able to replicate in Lec8 cells and infectious progeny viruses are released these cells. 


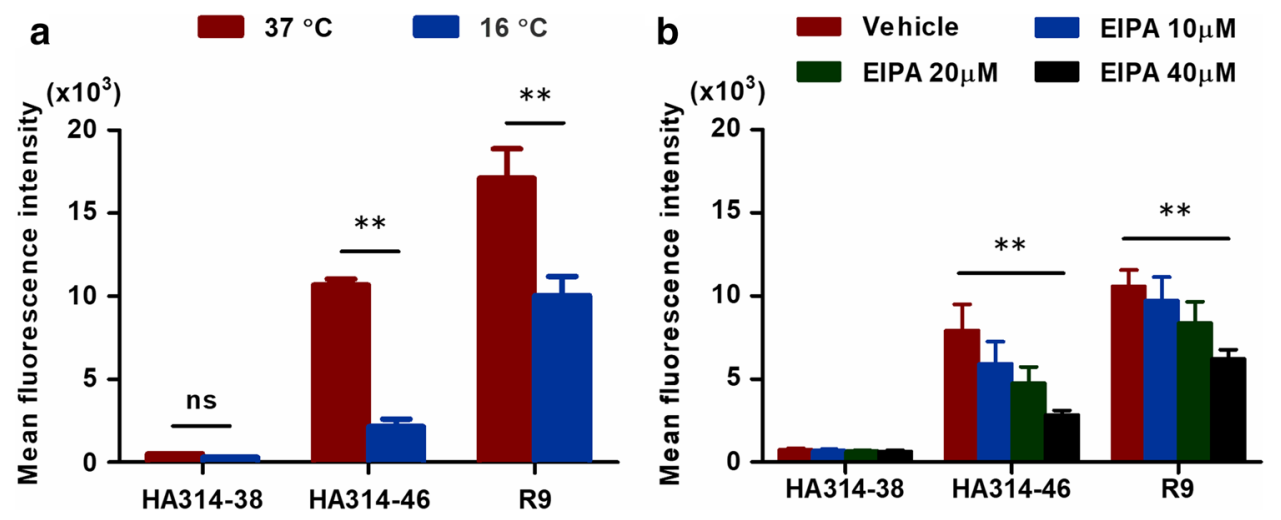

Figure 4. HA314-46 peptide is internalised through an energy-dependent endocytotic pathway. (a) Influence of incubation temperature on HA314-46 peptide uptake. KU812 cells were incubated with $10 \mu \mathrm{g} / \mathrm{mL}$ of FITCconjugated HA314-38, HA314-46, or R9 peptide for 60 min at 37 or $16^{\circ} \mathrm{C}$. (b) Effect of EIPA on HA314-46 peptide uptake. KU812 cells were pre-treated with vehicle (DMSO) or EIPA (10, 20, $40 \mu \mathrm{M})$ for $30 \mathrm{~min}$ at 37 ${ }^{\circ} \mathrm{C}$. Then, the cells were incubated with $10 \mu \mathrm{g} / \mathrm{mL}$ of FITC-conjugated HA314-38, HA314-46, or R9 peptide for $60 \mathrm{~min}$ at $37^{\circ} \mathrm{C}$. MFI of FITC in viable cells was analysed by flow cytometry. Data are presented as mean + SEM $(\mathrm{n}=3$ or 7$)$. Asterisks indicate significant decrease by two-way ANOVA with Bonferroni's multiple comparison test. ${ }^{* *} p<0.01 ;$ ns, not significant.
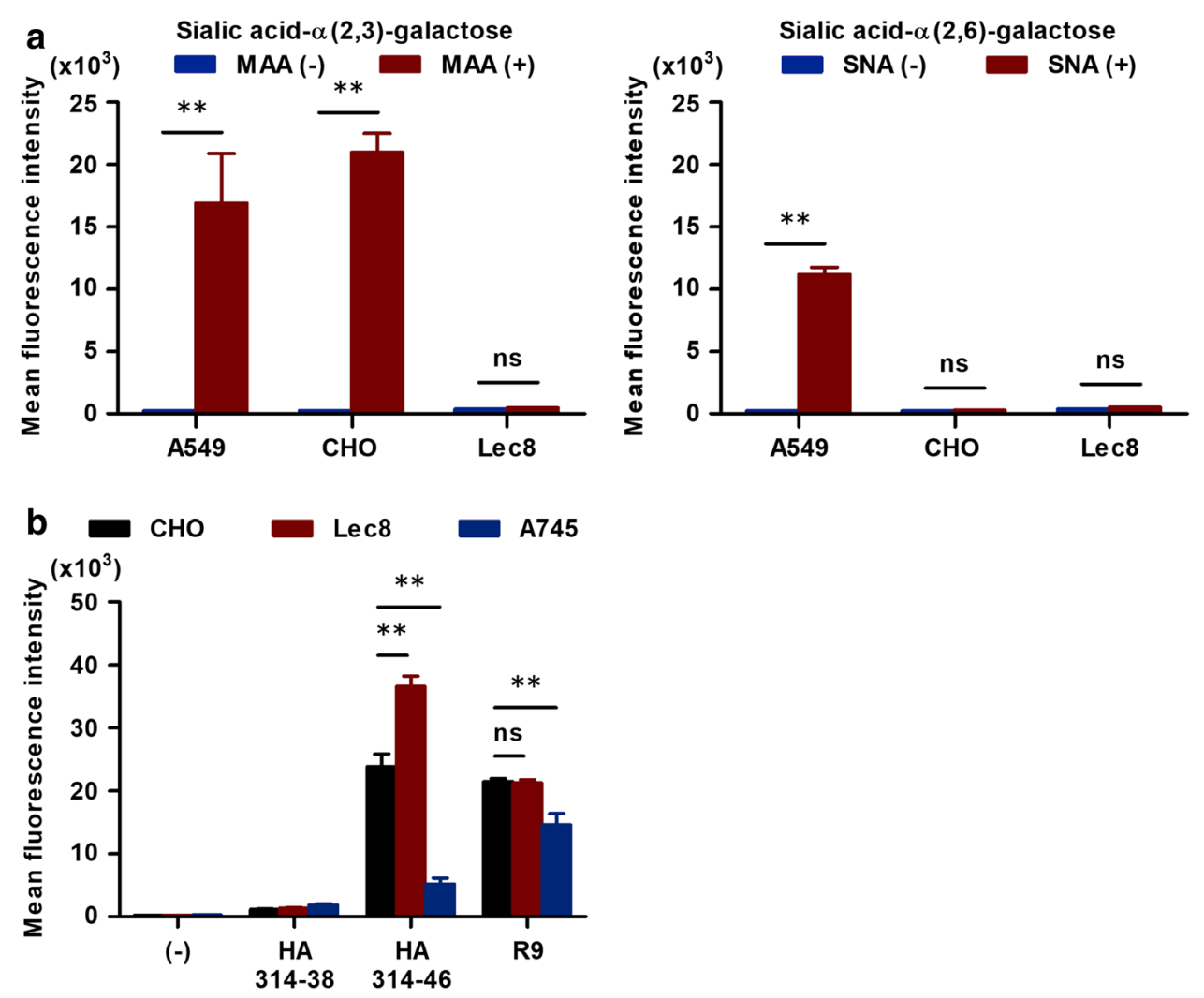

Figure 5. HA314-46 peptide internalisation is unconstrained by sialic acid residues. (a) Cell surface levels of $\alpha(2,3)$ - and $\alpha(2,6)$-linked sialic acid-galactose on A549, CHO-K1 and Lec8 cells. The cells were stained with FITC-conjugated MAA or SNA lectin for $15 \mathrm{~min}$ at $24-28^{\circ} \mathrm{C}$. (b) Cell-penetrating activity of HA314-46 peptide in CHO-K1, Lec8 and pgsA-745 cells. These cells were incubated with $10 \mu \mathrm{g} / \mathrm{mL}$ of FITC-conjugated HA314-38, HA314-46, or R9 peptide for $60 \mathrm{~min}$ at $37^{\circ} \mathrm{C}$. MFI of FITC in viable cells was determined by flow cytometry. Data are presented as mean + SEM $(n=3)$. Asterisks indicate significant difference by two-way ANOVA with Bonferroni's multiple comparison test. ${ }^{*} p<0.01$; ns, not significant. 


\begin{tabular}{|l|l|l|l|}
\hline Reassortant viruses & HA origins & Proteases & C-terminal amino acid sequences of HA1 \\
\hline PR8 & A/Puerto Rico/8/34 (H1N1) & Trypsin & RSAKLRMVTGLRNIPSIQSR/ \\
\hline UT3040HA (R339G)/PR8 & A/Vietnam/UT3040/04 (H5N1) & Trypsin & KSNRLVLATGLRNSPQGER/RR/K/K/R/ \\
\hline UT3040HA (R339G)/PR8 & A/Vietnam/UT3040/04 (H5N1) & Furin & KSNRLVLATGLRNSPQGERRRKKR/ \\
\hline
\end{tabular}

Table 2. Origin and partial amino acid sequences of HA proteins of reassortant viruses. Multiple basic amino acids critical for CPP activity are shown in bold font. The underlined letters and slashes indicate the mutation site at position 339 and the predicted sites of proteolytic cleavage, respectively.

\section{Discussion}

Here, we demonstrated that HA314-46, 33-amino acids in the C-terminus of H5N1 HPAIV HA1 protein, functioned as a CPP in vitro and in vivo. Moreover, both the cysteine residue at position 318 and multiple basic amino acids were of determined to be of critical importance for cell-penetrating activity. We also demonstrated that HA314-46 activity might contribute to H5N1 HPAIV entry through sialic acid-independent endocytotic pathway. To our knowledge, this is the first report to demonstrate that CPP is involved in the cellular entry of influenza A virus.

CPPs are short protein fragments that can pass through cell membranes and tissue barriers ${ }^{17}$. Since their first discovery in 1988, numerous CPPs have been reported ${ }^{35}$. However, there are several pitfalls in this field. One of the most critical issues is the insufficient experimental methods to evaluate the localisation and amount of uptake ${ }^{36,37}$. For example, flow cytometry is frequently used to quantitatively measure the uptake of peptides, however, it is difficult to discriminate between internalised and cell surface bound peptides using only this method. Here, using two different techniques, namely confocal microscopy and flow cytometry, we showed here that the C-terminal domain of H5N1 HPAIV HA1 protein functioned as a CPP. In this study, the HA314-46 internalisation was further confirmed using $0.1 \%$ Trypsin-EDTA treatment for $10 \mathrm{~min}$ at $37^{\circ} \mathrm{C}$ after peptide incubation to circumvent the non-specific binding of the peptides on the cell surface. Although our findings were inconsistent with those of a recent brief report that described the shorter sequence (SPQRESRRKKR) of H5 HA cleavage site acts as a $\mathrm{CPP}^{38}$, the controversial results may have been due to their evaluation of cellular uptake using flow cytometry without efficient treatment with a protease, such as trypsin. The discrepancy should be carefully evaluated in further studies. Additionally, in a screening assay for HA peptide with cell-penetrating activity, we demonstrated that the cysteine residue played a pivotal role in the cell-penetrating activity of HA314-46. Although our findings indicate that disulphide-linked HA314-46 homodimers also possess the cell-penetrating activity, the functional role of the cysteine residue at position 318 remains unclear.

The cellular uptake mechanisms of CPPs are the subject of intense investigation ${ }^{37}$. First, we conducted a temperature dependent assay to assess the involvement of endocytosis. Similar to R9, the cell-penetrating activity of HA314-46 was attenuated at $16^{\circ} \mathrm{C}$ which blocks energy-dependent processes without affecting membrane fluidity ${ }^{36,39}$. Moreover, HA314-46 internalisation was inhibited by the treatment of EIPA. Together, these results suggest that the cell-penetrating activity of HA314-46 is mediated by an energy-dependent endocytic pathway, such as macropinocytosis. Cationic CPPs have been thought to electrically interact with anionic plasma membrane components such as proteoglycans ${ }^{33}$. In addition, two reports that show interaction of oligo-arginine with CXC chemokine receptor type $4^{40}$ and binding of CendR peptide to neurophilin- $1^{41}$ must be noted. In our study, HA314-46 internalisation is not abolished in sialic acid-deficient cells, however, it is markedly reduced by trypsin pre-treatment of cell surface. These results suggest the existence of proteinaceous receptors on the host cells for HA314-46. Although HA314-46 is able to penetrate into various types of cells, there was marked difference in uptake efficiency between KU812 and HL-60 cells. This result may be useful in identifying the specific receptor. In the present study, proteoglycans were associated with HA314-46 peptide uptake, however, it remains uncertain whether proteoglycans act as a host cell receptor in the sialic acid-independent cellular entry of H5N1 HPAIV. The reason might be the abundance of sialic acid- $\alpha(2,3)$-galactose on pgsA-745 cells. The interactions of proteoglycans with HA314-46 during H5N1 HPAIV infection may be covered by the predominant pathway through sialic acid on the cell surface. Therefore, this warrants further investigation to fully elucidate the cellular entry mechanism of HA314-46.

The mechanism of viral transmission has been garnering attention in influenza virus research ${ }^{42}$. In $\mathrm{H} 5 \mathrm{~N} 1$ HPAIVs, many studies have focused on the affinity and specificity of HA for sialic acid receptor ${ }^{42-44}$. However, the tropism of $\mathrm{H} 5 \mathrm{~N} 1$ avian influenza viruses does not necessarily correlate with the distribution pattern of sialic acid ${ }^{45,46}$. Moreover, H5N1 viruses are shown to have an ability to infect sialidase-treated human bronchial epithelial cells ${ }^{47}$. H5N1 HPAIV viruses can also infect epithelial cells of the human upper respiratory tract, such as nasopharynx, adenoid and tonsil, despite the lack of sialic acid- $\alpha(2,3)$-galactose ${ }^{48}$. These reports suggest that other viral factors may affect the transmission of $\mathrm{H} 5 \mathrm{~N} 1$ avian influenza viruses. Using reassortant virus with $\mathrm{H} 5$ HA and recombinant furin, we found that the cell-penetrating activity of HA314-46 might contribute to sialic acid-independent cellular entry of H5N1 HPAIV. The reason why this alternative entry route has not been noted before, might be accounted for by the partial cleavage of HA314-46 sequence by proteases at the multiple sites or the total degradation; that is, to exert the cell-penetrating activity of HA314-46 during H5N1 HPAIV infection, multiple basic amino acids, which are crucial domains for cell-penetrating activity, need to be cleaved accurately at the C-terminus of HA1 protein (RRRKKR/GLF) by proteases such as furin. Another possible reason may be the location of the cleavage site within the HA protein. Although the cleavage site protrudes from the surface, it is located in a prominent loop distant from the receptor binding site in the globular head region ${ }^{11}$. Similar 
a

PR8 UT3040HA(R339G)/PR8 $(-)$ Trypsin Furin
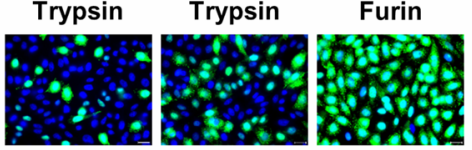

$* *$

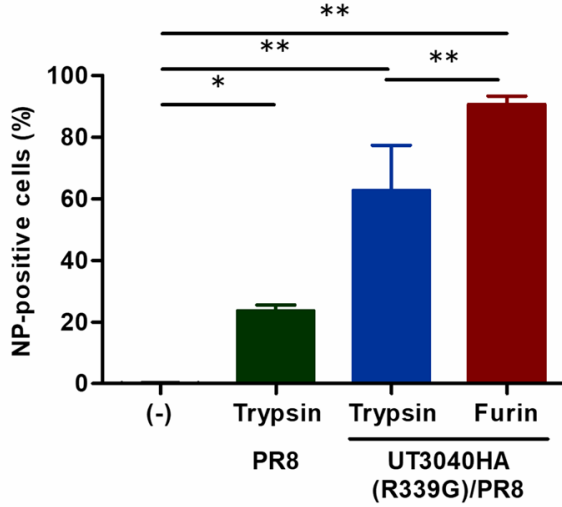

C
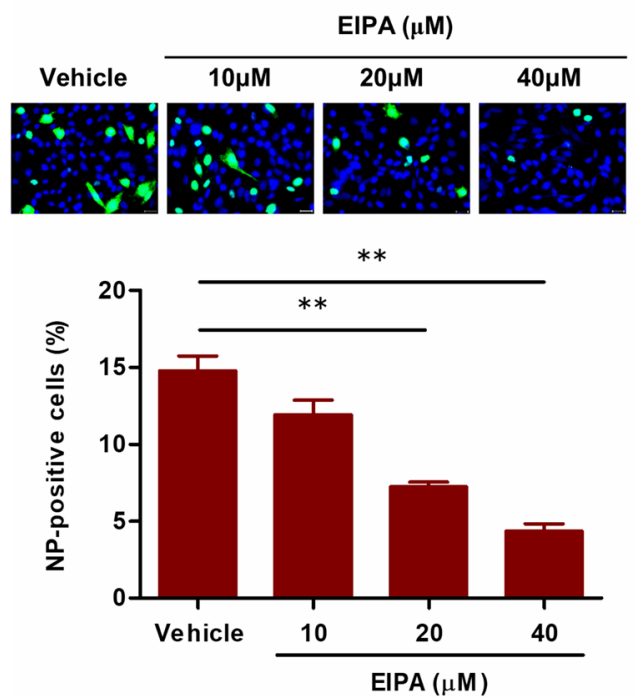

b PR8 UT3040HA(R339G)/PR8
$(-)$
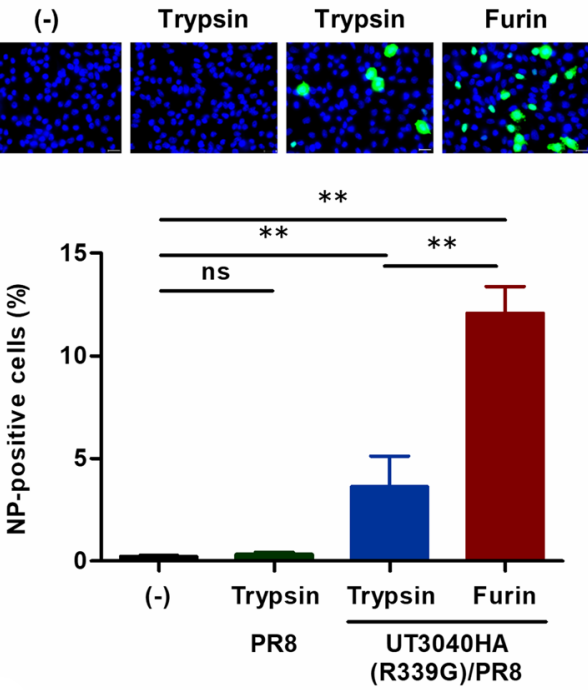

d
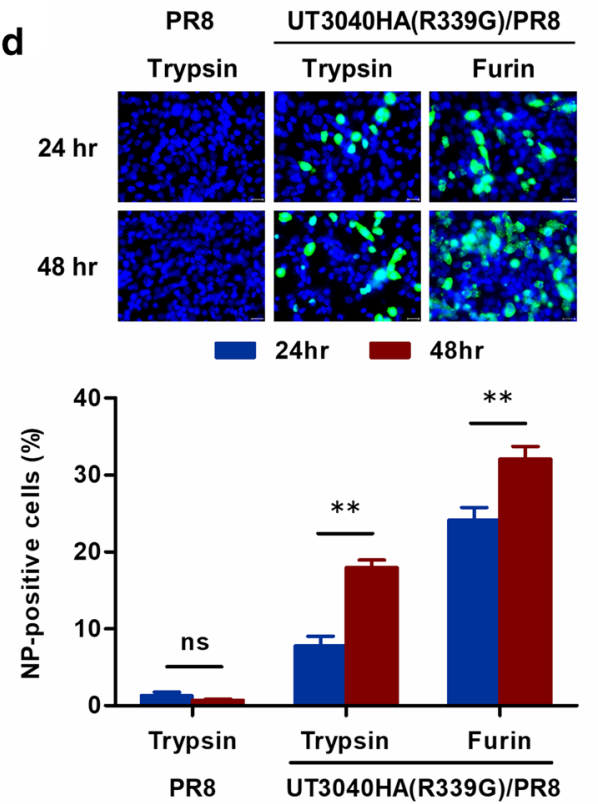

Figure 6. Cell-penetrating activity of HA314-46 drives sialic acid-independent virus internalisation. (a, b) Entry of reassortant viruses into CHO-K1 and Lec8 cells. CHO-K1 (a) and Lec8 (b) cells were incubated with trypsin- or furin-treated reassortant viruses at $37^{\circ} \mathrm{C}$ for $1 \mathrm{~h}$ at MOI of 10 . After washing and incubation for $8 \mathrm{~h}$ in the culture medium, the cells were fixed in $4 \%$ paraformaldehyde. (c) Effect of EIPA on sialic acidindependent entry of furin-treated UT3040HA (R339G)/PR8 viruses. Lec8 cells were pre-treated with vehicle (DMSO) or EIPA $(10,20,40 \mu \mathrm{M})$ for $30 \mathrm{~min}$ at $37^{\circ} \mathrm{C}$ and then were incubated with furin-treated UT3040HA (R339G)/PR8 viruses as described in (b). After washing, the cells were further incubated for $8 \mathrm{~h}$ in the culture medium containing vehicle or EIPA. (d) Propagation of UT3040HA (R339G)/PR8 virus in Lec8 cells. Lec8 cells were treated with reassortant viruses as described in (b). After washing, the cells were incubated in the culture medium at $37^{\circ} \mathrm{C}$ for 24 and $48 \mathrm{~h}$. The fixed cells were permeabilised and stained with anti-influenza A nucleoprotein monoclonal antibody (a-d). Localisation of the viruses was evaluated by fluorescent microscopy. Representative images from four or six experiments are shown. Green; viral nucleoprotein, Blue; nucleus. Scale bar, $20 \mu \mathrm{m}$. The graphs in the bottom panels indicate the proportion of viral nucleoprotein-positive cells by flow cytometric analysis. Data are presented as mean + SEM $(n=4$ or 6$)$. Asterisks indicate significant difference by one-way ANOVA with Bonferroni’s multiple comparison test. ${ }^{* *} p<0.01 ;{ }^{*} p<0.05$; ns, not significant.

to HA314-46 peptide, the alternative virus entry pathway occurred by endocytosis, and virus replication was observed in sialic acid-deficient cells. Therefore, our findings propose a sialic acid-independent mechanism in which H5N1 HPAIV invades host cells by using CPP activity. Additional studies expanding our findings to 
animal models are needed to understand the significance of HA314-46-mediated cellular entry in the infectivity and pathogenicity of H5N1 HPAIVs.

In conclusion, we discovered that H5N1 HPAIV has the potential to infect host cells by using CPP activity of the C-terminal domain of the HA1 protein. These findings provide novel insights into the role of HA cleavage site motif during virus infection and may help us to better understand the mechanism of H5N1 HPAIV infection.

\section{Methods}

Peptides. All peptides were synthesised and purified to greater than 95\% for in vitro and in vivo applications (Toray Research Center, Inc., Kamakura, Japan). The qualities were confirmed using reverse-phase highperformance liquid chromatography and mass spectrometry. For detection of peptide internalisation, FITC was conjugated at the $\mathrm{N}$-terminus of a peptide through a 6-aminohexanoic acid linker. FITC-conjugated peptides were dissolved in sterile deionised water at $1 \mathrm{mg} / \mathrm{mL}$, aliquoted and stored at $-80^{\circ} \mathrm{C}$ until use.

Cells. Cell lines were purchased from JCRB Cell Bank (Osaka, Japan), RIKEN BRC (Tsukuba, Japan) or ATCC (Manassas, VA, USA). COS-7, A549, MDCK, and 293 T cells were maintained in Dulbecco's modified Eagle medium (DMEM) (Nacalai Tesque, Inc., Kyoto, Japan) supplemented with $10 \%$ foetal bovine serum (FBS), $100 \mathrm{unit} / \mathrm{mL}$ penicillin, $100 \mu \mathrm{g} / \mathrm{mL}$ streptomycin and $1 \mathrm{mM}$ sodium pyruvate (Gibco, Grand Island, NY, USA). KU812 cells were cultured in RPMI-1640 (Gibco) supplemented with 10\% FBS, $100 \mathrm{unit} / \mathrm{mL}$ penicillin, and $100 \mu \mathrm{g} / \mathrm{mL}$ streptomycin. $\mathrm{CHO}-\mathrm{K} 1, \mathrm{Lec} 8$, and pgsA-745 cells were maintained in minimum essential medium eagle, alpha modification ( $\alpha$-MEM) (Nacalai Tesque, Inc.) supplemented with 10\% FBS, $100 \mathrm{unit} / \mathrm{mL}$ penicillin and $100 \mu \mathrm{g} / \mathrm{mL}$ streptomycin. These cells were cultured at $37^{\circ} \mathrm{C}$ in $5 \% \mathrm{CO}_{2}$. In the experiments using mouse primary cells, splenocytes were freshly isolated from surgically excised spleens of naïve C57BL/6 N mice (CLEA Japan, Inc., Tokyo, Japan). All mice experiments were approved by the animal experiment committee of the Tokyo Metropolitan Institute of Medical Science (Permission number: 13075) and were conducted in accordance with the ethical guidelines for animal experiments of the Tokyo Metropolitan Institute of Medical Science.

Confocal microscopy imaging. COS-7 cells $\left(6 \times 10^{4}\right.$ cells) were cultured overnight on glass slides (Matsunami Glass Ind. Ltd., Osaka, Japan) using flexiPERM slide (SARSTEDT AG \& Co. KG, Numbrecht, Germany). After washing with Dulbecco's phosphate-buffered saline (D-PBS), cells were incubated with $10 \mu \mathrm{g} / \mathrm{mL}$ FITClabelled peptides or serum-free Opti-MEM (Gibco) for $60 \mathrm{~min}$ at $37^{\circ} \mathrm{C}$. Nuclei were stained with Hoechst 34580 (Sigma-Aldrich, St Louis, MO, USA). After washing, the localisations of fluorescent peptides were observed in living cells without fixing. KU812 cells $\left(2.5 \times 10^{5}\right.$ cells $)$ were incubated with $10 \mu \mathrm{g} / \mathrm{mL}$ FITC-labelled peptides or Opti-MEM in 96-well plates for $60 \mathrm{~min}$. To remove peptides non-specifically bound on cell surface, cells were treated with $0.1 \%$ trypsin-EDTA for $10 \mathrm{~min}$ at $37^{\circ} \mathrm{C}$. After washing, cytospin slides were prepared and mounted with ProLong Gold Antifade Mountant with DAPI (Molecular Probes, Inc., Eugene, OR, USA). Slides were examined by a LSM710 confocal laser scanning microscope (ZEISS, Oberkochen, Germany). Images were processed using the ZEN 2.3 SP1 software version 14 (https://www.zeiss.co.jp/microscopy/products/microscope -software/zen.html).

Flow cytometric analysis. COS-7 cells $\left(2 \times 10^{4}\right.$ cells $)$ were cultured in 24 -well plates for one day. CHO$\mathrm{K} 1$, Lec8 and pgsA-745 cells $\left(3 \times 10^{4}\right.$ cells) were grown in 24 -well plates for two days. After washing with D-PBS, these adherent cells were incubated with $10 \mu \mathrm{g} / \mathrm{mL}$ FITC-labelled peptides or Opti-MEM for $60 \mathrm{~min}$ at $37^{\circ} \mathrm{C}$ and then harvested by $0.25 \%$ trypsin-EDTA treatment. KU812 cells and splenocytes $\left(2.5 \times 10^{5}\right.$ cells $)$ were incubated with $10 \mu \mathrm{g} / \mathrm{mL}$ FITC-labelled peptides or Opti-MEM in 96-well plates for $60 \mathrm{~min}$ and then treated with $0.1 \%$ trypsin-EDTA for $10 \mathrm{~min}$ at $37^{\circ} \mathrm{C}$. After Fc-receptor blocking by incubation with anti-mouse CD16/CD32 (BD Biosciences, San Jose, CA, USA), splenocytes were stained with antibodies against CD8a, CD19, B220, F4/80, I-A/I-E (BioLegend, San Diego, CA), CD3e, CD4, and CD11b (BD Biosciences) for 30 min on ice. For experiments with macropinocytosis inhibitor, KU812 cells were treated with 10, 20, and $40 \mu \mathrm{M}$ EIPA for 30 min at $37^{\circ} \mathrm{C}$ and then incubated with $10 \mu \mathrm{g} / \mathrm{mL}$ FITC-labelled peptides in the presence of EIPA. Data were obtained using BD FACSCantoII flow cytometer (BD Biosciences) and geometric MFI of FITC in 7-aminoactinomycin D (Sigma-Aldrich)-negative viable cells was analysed using FlowJo software version 10 (https://www.flowjo.com/ solutions/flowjo) (Tree Star, Inc., Ashland, OR, USA).

Immunohistochemical analysis of murine intranasal inhalation model. Isoflurane-anaesthetised $\mathrm{C} 57 \mathrm{BL} / 6 \mathrm{~N}$ mice were challenged with intranasal administration of $25 \mu \mathrm{g}$ of FITC-conjugated peptides or saline. Lung tissues were isolated at $15 \mathrm{~min}$ after inhalation and fixed in $10 \%$ formalin neutral buffer solution (Wako Pure Chemical Industries, Ltd., Osaka, Japan). The tissues were embedded in O.C.T. Compound (Sakura Finetek Japan Co. Ltd., Tokyo, Japan) and sectioned continuously at $10-\mu \mathrm{m}$ thickness. After washing, sections were permeabilised with $0.3 \%$ PBS-T, blocked with normal rabbit serum, and stained with Fluorescein/Oregon Green polyclonal antibody and Alexa Fluor 555-conjugated donkey anti-rabbit IgG $(\mathrm{H}+\mathrm{L})$ highly cross-adsorbed secondary antibody (Molecular Probes) for $60 \mathrm{~min}$ at $24-28{ }^{\circ} \mathrm{C}$. Serial sections were counterstained with Haematoxylin and Eosin (H\&E) dyes (Wako Pure Chemical Industries, Ltd.). Fluorescent images and bright-field pictures were obtained using an LSM710 confocal laser scanning microscope and a BZ-9000 microscope (KEYENCE Corp., Osaka, Japan), respectively. 
Sialic acid-galactose levels on cell surface. A549, CHO-K1, and Lec8 cells were stained with FITCconjugated MAA or SNA lectin (EY Laboratories, Inc., San Mateo, CA, USA) at $24-28^{\circ} \mathrm{C}$ for $15 \mathrm{~min}$. Data were acquired using BD FACSCantoII flow cytometer and analysed using FlowJo software version 10.

Generation of reassortant viruses by reverse genetics. HA gene of A/Vietnam/UT3040/2004 $(\mathrm{H} 5 \mathrm{~N} 1)$ virus was cloned to generate reassortant viruses by reverse genetics. Viral RNA was extracted from culture supernatant containing infectious virus using ISOGEN II (NipponGene Co., Ltd. Tokyo, Japan). The cDNA was prepared by reverse transcription using SuperScript VILO cDNA Synthesis kit (Life Technologies, Carlsbad, CA, USA). Then, full-length HA gene of A/Vietnam/UT3040/2004 was amplified with gene-specific universal primer sets as described by Hoffmann et al. ${ }^{49}$. The amplified HA gene was directly cloned into BsmBI-digested pHW2000 expression vector using the In-Fusion HD Cloning kit (Takara Bio USA, Inc. Mountain View, CA, USA) according to the manufacturer's instructions. The pHW2000 vector for the expression of A/Vietnam/ UT3040/2004 HA mutant (UT3040HA (R339G)) was generated by PCR-based mutagenesis. All constructs were sequenced and analysed with ABI PRISM 3100 Genetic Analyser (Applied Biosystems, Foster City, CA, USA).

For generating reassortant viruses and parental A/Puerto Rico/8/1934 (H1N1) virus, MDCK and 293 T cells were co-transfected with eight pHW2000 vectors ( $1 \mu \mathrm{g}$ of each vector) using $16 \mu \mathrm{L}$ of TransIT-293 Reagent (Takara Bio USA, Inc.). Twenty-four hours after transfection, Opti-MEM containing $1 \mu \mathrm{g} / \mathrm{mL}$ trypsin acetylated from bovine pancreas (Sigma-Aldrich) or recombinant human furin (Peprotech, Rocky Hill, NJ, USA) was added, and the cells were incubated for $48 \mathrm{~h}$ at $37^{\circ} \mathrm{C}$. The collected viruses were further propagated in MDCK cells grown in DMEM (Nissui Pharmaceutical Co., Ltd., Tokyo, Japan) supplemented with $1 \mu \mathrm{g} / \mathrm{mL}$ trypsin acetylated from bovine pancreas or recombinant human furin and $1 \%$ bovine serum albumin (Sigma-Aldrich) at $37^{\circ} \mathrm{C}$ for $48 \mathrm{~h}$. The culture supernatants were titrated by plaque assay using MDCK cells and were stored in aliquots at $-80^{\circ} \mathrm{C}$ until use. HA genes of the collected viruses were sequenced to verify the absence of undesired mutations. All procedures using reassortant viruses were performed in biosafety level 3 facilities by personnel wearing powered air-purifying respirators.

Virus infection assay. CHO-K1 and Lec8 cells $\left(2 \times 10^{4}\right.$ cells $)$ were cultured for three days in 12 -well plates. These cells were incubated with reassortant viruses at an MOI 10 for $60 \mathrm{~min}$ at $37^{\circ} \mathrm{C}$. After washing, the cells were cultured in a-MEM containing 10\% FBS, $100 \mathrm{unit} / \mathrm{mL}$ penicillin, and $100 \mu \mathrm{g} / \mathrm{mL}$ streptomycin for 8,24 , or $48 \mathrm{~h}$. For the macropinocytosis inhibition study, Lec8 cells were pre-incubated with 10, 20, and $40 \mu \mathrm{M}$ EIPA for $30 \mathrm{~min}$ at $37^{\circ} \mathrm{C}$ and infected with furin-treated UT3040HA (R339G)/PR8 reassortant virus as mentioned above. Cells were incubated for an additional $8 \mathrm{~h}$ in the presence or absence of EIPA. The infected cells were fixed in $4 \%$ paraformaldehyde, permeabilised with $0.5 \%$ Triton-X for immunofluorescence or BD Perm/Wash buffer (BD Biosciences) for flow cytometry, and stained with anti-influenza A nucleoprotein antibody (Clone HB65) and Alexa Fluor 488-conjugated goat anti-mouse IgG $(\mathrm{H}+\mathrm{L})$ secondary antibody (Jackson ImmunoResearch Inc., West Grove, PA, USA) for $60 \mathrm{~min}$ at $24-28{ }^{\circ} \mathrm{C}$. Cells were mounted with ProLong Gold Antifade Mountant with DAPI, and fluorescent images were acquired with a BZ-9000 microscope. The percentages of influenza nucleoprotein-positive cells were analysed by BD FACSCantoII flow cytometer and FlowJo software version 10.

Statistical analysis. Data are presented as mean + standard error of the mean (SEM). Statistical significance was calculated using GraphPad Prism software version 5 (San Diego, CA, USA). Statistical tests and specific $p$-values are indicated in the figure legends.

\section{Data availability}

The datasets generated during and/or analysed during the current study are available from the corresponding author on reasonable request.

Received: 10 February 2020; Accepted: 1 October 2020

Published online: 22 October 2020

\section{References}

1. Neumann, G., Noda, T. \& Kawaoka, Y. Emergence and pandemic potential of swine-origin H1N1 influenza virus. Nature 459, 931-939 (2009).

2. Neumann, G., Chen, H., Gao, G. F., Shu, Y. \& Kawaoka, Y. H5N1 influenza viruses: outbreaks and biological properties. Cell Res. 20, 51-61 (2010)

3. Yuen, K. Y. et al. Clinical features and rapid viral diagnosis of human disease associated with avian influenza A H5N1 virus. Lancet 351, 467-471 (1998)

4. Claas, E. C. et al. Human influenza A H5N1 virus related to a highly pathogenic avian influenza virus. Lancet 351, 472-477 (1998).

5. Abdel-Ghafar, A. N. et al. Update on avian influenza A (H5N1) virus infection in humans. New Engl. J. Med. 358, 261-273 (2008).

6. Korteweg, C. \& Gu, J. Pathology, molecular biology, and pathogenesis of avian influenza A (H5N1) infection in humans. Am. J. Pathol. 172, 1155-1170 (2008).

7. Wu, H. et al. Novel reassortant highly pathogenic H5N6 avian influenza viruses in poultry in China. Infect. Genet. Evol. 31, 64-67 (2015).

8. Zhao, K. et al. Characterization of three H5N5 and one H5N8 highly pathogenic avian influenza viruses in China. Vet. Microbiol. 163, 351-357 (2013).

9. Dou, D., Revol, R., Ostbye, H., Wang, H. \& Daniels, R. Influenza A virus cell entry, replication, virion assembly and movement. Front. Immunol. 9, 1581 (2018).

10. Medina, R. A. \& Garcia-Sastre, A. Influenza A viruses: new research developments. Nat. Rev. Microbiol. 9, 590-603 (2011).

11. Bottcher-Friebertshauser, E., Klenk, H. D. \& Garten, W. Activation of influenza viruses by proteases from host cells and bacteria in the human airway epithelium. Pathog. Dis. 69, 87-100 (2013). 
12. Luczo, J. M., Stambas, J., Durr, P. A., Michalski, W. P. \& Bingham, J. Molecular pathogenesis of H5 highly pathogenic avian influenza: the role of the haemagglutinin cleavage site motif. Rev. Med. Virol. 25, 406-430 (2015).

13. Stieneke-Grober, A. et al. Influenza virus hemagglutinin with multibasic cleavage site is activated by furin, a subtilisin-like endoprotease. EMBO J. 11, 2407-2414 (1992).

14. Horimoto, T., Nakayama, K., Smeekens, S. P. \& Kawaoka, Y. Proprotein-processing endoproteases PC6 and furin both activate hemagglutinin of virulent avian influenza viruses. J. Virol. 68, 6074-6078 (1994).

15. Feldmann, A., Schafer, M. K., Garten, W. \& Klenk, H. D. Targeted infection of endothelial cells by avian influenza virus A/FPV/ Rostock/34 (H7N1) in chicken embryos. J. Virol. 74, 8018-8027 (2000).

16. Park, J. et al. Mutational analysis of a human immunodeficiency virus type 1 Tat protein transduction domain which is required for delivery of an exogenous protein into mammalian cells. J. Gen. Virol. 83, 1173-1181 (2002).

17. Guidotti, G., Brambilla, L. \& Rossi, D. Cell-penetrating peptides: From basic research to clinics. Trends Pharmacol. Sci. 38, 406-424 (2017).

18. Koren, E. \& Torchilin, V. P. Cell-penetrating peptides: breaking through to the other side. Trends Mol. Med. 18, 385-393 (2012).

19. Green, M. \& Loewenstein, P. M. Autonomous functional domains of chemically synthesized human immunodeficiency virus tat trans-activator protein. Cell 55, 1179-1188 (1988).

20. Frankel, A. D. \& Pabo, C. O. Cellular uptake of the tat protein from human immunodeficiency virus. Cell 55, 1189-1193 (1988).

21. Elliott, G. \& O’Hare, P. Intercellular trafficking and protein delivery by a herpesvirus structural protein. Cell 88, 223-233 (1997).

22. Freire, J. M. et al. Nucleic acid delivery by cell penetrating peptides derived from dengue virus capsid protein: design and mechanism of action. FEBS J 281, 191-215 (2014).

23. Montrose, K., Yang, Y., Sun, X., Wiles, S. \& Krissansen, G. W. Xentry, a new class of cell-penetrating peptide uniquely equipped for delivery of drugs. Sci. Rep. 3, 1661. https://doi.org/10.1038/srep01661 (2013).

24. Montrose, K., Yang, Y. \& Krissansen, G. W. X-pep, a novel cell-penetrating peptide motif derived from the hepatitis B virus. Biochem. Biophys. Res. Commun. 453, 64-68 (2014).

25. Zhang, P., Monteiro da Silva, G., Deatherage, C., Burd, C. \& DiMaio, D. Cell-penetrating peptide mediates intracellular membrane passage of human papillomavirus L2 protein to trigger retrograde trafficking. Cell 174, 1465-1476.e1413 (2018).

26. Lee, J. E. \& Lim, H. J. LDP12, a novel cell-permeable peptide derived from L1 capsid protein of the human papillomavirus. Mol. Biol. Rep. 39, 1079-1086 (2012).

27. Faust, T. B., Binning, J. M., Gross, J. D. \& Frankel, A. D. Making sense of multifunctional proteins: human immunodeficiency virus type 1 accessory and regulatory proteins and connections to transcription. Annu. Rev. Virol. 4, 241-260 (2017).

28. Richard, J. P. et al. Cell-penetrating peptides. A reevaluation of the mechanism of cellular uptake. J. Biol. Chem. 278, 585-590 (2003).

29. Tam, J. P., Wu, C. R., Liu, W. \& Zhang, J. W. Disulfide bond formation in peptides by dimethyl sulfoxide. Scope and applications. J. Am. Chem. Soc. 113, 6657-6662 (1991).

30. Duchardt, F., Fotin-Mleczek, M., Schwarz, H., Fischer, R. \& Brock, R. A comprehensive model for the cellular uptake of cationic cell-penetrating peptides. Traffic 8, 848-866 (2007).

31. Han, J. et al. Genome-wide CRISPR/Cas9 screen identifies host factors essential for influenza virus replication. Cell Rep. 23, 596-607 (2018).

32. Deutscher, S. L. \& Hirschberg, C. B. Mechanism of galactosylation in the Golgi apparatus. A Chinese hamster ovary cell mutant deficient in translocation of UDP-galactose across Golgi vesicle membranes. J. Biol. Chem. 261, 96-100 (1986).

33. Nakase, I. et al. Interaction of arginine-rich peptides with membrane-associated proteoglycans is crucial for induction of actin organization and macropinocytosis. Biochemistry 46, 492-501 (2007).

34. Esko, J. D., Stewart, T. E. \& Taylor, W. H. Animal cell mutants defective in glycosaminoglycan biosynthesis. Proc. Natl. Acad. Sci. USA 82, 3197-3201 (1985).

35. Milletti, F. Cell-penetrating peptides: classes, origin, and current landscape. Drug Discov. Today. 17, 850-860 (2012).

36. Patel, L. N., Zaro, J. L. \& Shen, W. C. Cell penetrating peptides: intracellular pathways and pharmaceutical perspectives. Pharm Res. 24, 1977-1992 (2007).

37. Madani, F., Lindberg, S., Langel, U., Futaki, S. \& Graslund, A. Mechanisms of cellular uptake of cell-penetrating peptides. J. Biophys. 2011, 414729. https://doi.org/10.1155/2011/414729 (2011).

38. Yamamoto, Y., Tamiya, S., Shibuya, M., Nakase, I. \& Yoshioka, Y. Peptides with the multibasic cleavage site of the hemagglutinin from highly pathogenic influenza viruses act as cell-penetrating via binding to heparan sulfate and neuropilins. Biochem. Biophys. Res. Commun. 512, 453-459 (2019).

39. Zaro, J. L. \& Shen, W. C. Evidence that membrane transduction of oligoarginine does not require vesicle formation. Exp. Cell Res. 307, 164-173 (2005).

40. Tanaka, G. et al. CXCR4 stimulates macropinocytosis: implications for cellular uptake of arginine-rich cell-penetrating peptides and HIV. Chem. Biol. 19, 1437-1446 (2012).

41. Teesalu, T., Sugahara, K. N., Kotamraju, V. R. \& Ruoslahti, E. C-end rule peptides mediate neuropilin-1-dependent cell, vascular, and tissue penetration. Proc. Natl. Acad. Sci. USA 106, 16157-16162 (2009).

42. Neumann, G. \& Kawaoka, Y. Transmission of influenza A viruses. Virology 479-480, 234-246 (2015).

43. Imai, M. et al. Experimental adaptation of an influenza H5 HA confers respiratory droplet transmission to a reassortant H5 HA/ H1N1 virus in ferrets. Nature 486, 420-428 (2012).

44. Yamada, S. et al. Haemagglutinin mutations responsible for the binding of $\mathrm{H} 5 \mathrm{~N} 1$ influenza A viruses to human-type receptors. Nature 444, 378-382 (2006).

45. Yao, L., Korteweg, C., Hsueh, W. \& Gu, J. Avian influenza receptor expression in H5N1-infected and noninfected human tissues. FASEB J. 22, 733-740 (2008).

46. Guo, Y. et al. Analysis of hemagglutinin-mediated entry tropism of H5N1 avian influenza. Virol. J. 6, 39. https://doi. org/10.1186/1743-422x-6-39 (2009).

47. Oshansky, C. M. et al. Avian influenza viruses infect primary human bronchial epithelial cells unconstrained by sialic acid alpha2,3 residues. PLoS ONE 6, e21183. https://doi.org/10.1371/journal.pone.0021183 (2011).

48. Nicholls, J. M. et al. Tropism of avian influenza A (H5N1) in the upper and lower respiratory tract. Nat. Med. 13, 147-149 (2007).

49. Hoffmann, E., Stech, J., Guan, Y., Webster, R. G. \& Perez, D. R. Universal primer set for the full-length amplification of all influenza A viruses. Arch. Virol. 146, 2275-2289 (2001).

50. Bienert, S. et al. The SWISS-MODEL Repository-new features and functionality. Nucl. Acids Res. 45, D313-D319. https://doi. org/10.1093/nar/gkw1132 (2017).

\section{Acknowledgements}

The authors acknowledge Drs. Erich Hoffmann and Robert Webster, St. Jude Children's Research Hospital, Inc., for kindly providing pHW2000 plasmid vectors. We thank Dr. Yoshihiro Kawaoka, Division of Virology, Department of Microbiology and Immunology, Institute of Medical Science, University of Tokyo, for providing A/Vietnam/UT3040/2004 (H5N1) virus. We also appreciate Mayumi Shindo, Michiko Imanishi, Kyohei Mikami, 
Hiromi Kondo for their excellent technical assistance. We would like to thank Editage (www.editage.com) for English language editing. This work was supported by JSPS KAKENHI Grant Numbers JP25670066, JP17K10043, JP20K08854 and by the Tokyo Metropolitan Government, Japan.

\section{Author contributions}

N.K. designed the research and conducted in vitro and in vivo assays with assistance of N.N. and M.U. N.Y., M.K., F.Y., Y.S. and H.K. supported the experiments using influenza viruses. N.K., N.N., and M.U. analysed the data. N.K. wrote the manuscript through discussion with N.Y., M.K., F.Y., Y.S., H.K. and F.S. All authors reviewed the manuscript.

\section{Competing interests}

The authors declare no competing interests.

\section{Additional information}

Supplementary information is available for this paper at https://doi.org/10.1038/s41598-020-74604-w.

Correspondence and requests for materials should be addressed to F.S.

Reprints and permissions information is available at www.nature.com/reprints.

Publisher's note Springer Nature remains neutral with regard to jurisdictional claims in published maps and institutional affiliations.

(c) Open Access This article is licensed under a Creative Commons Attribution 4.0 International License, which permits use, sharing, adaptation, distribution and reproduction in any medium or format, as long as you give appropriate credit to the original author(s) and the source, provide a link to the Creative Commons licence, and indicate if changes were made. The images or other third party material in this article are included in the article's Creative Commons licence, unless indicated otherwise in a credit line to the material. If material is not included in the article's Creative Commons licence and your intended use is not permitted by statutory regulation or exceeds the permitted use, you will need to obtain permission directly from the copyright holder. To view a copy of this licence, visit http://creativecommons.org/licenses/by/4.0/.

(C) The Author(s) 2020 